\title{
CALCIUM CARBONATE GROWTH MODIFICATION BY CONSTITUENTS RELEASES FROM POROUS CELLULOSE FILTER MEMBRANES
}

\author{
ANDRÓNICO NEIRA-CARRILLO ${ }^{* 1}$, RANJITH KRISHNA PAi ${ }^{1,2}$, VICTOR FUENZALIDA ${ }^{3}$, M. SOLEDAD \\ FERNANDEZ ${ }^{1}$, JAIME RETUERT ${ }^{1,3+}$ AND JOSÉ LUIS ARIAS ${ }^{l}$
}

\author{
${ }^{1}$ Faculty of Veterinary and Animal Sciences, University of Chile and Center for Advanced Interdisciplinary Research in Materials (CIMAT). Santa Rosa 11735, \\ P.O. Box 2-15. La Pintana, Santiago, Chile. \\ ${ }^{2}$ Material Chemistry Research Group, Department of Physical Inorganic and Structural Chemistry, Arrhenius Laboratory, \\ Stockholm University, SE-106 91 Stockholm. \\ ${ }^{3}$ Faculty of Physics and Mathematics Science. Av. Tupper 2069, Box 2777, University of Chile. Santiago, Chile. \\ (Received: 3 December 2007 - Accepted: 12 March 2008)
}

\begin{abstract}
Filtration of a suspension of calcium carbonate $\left(\mathrm{CaCO}_{3}\right)$ or other inorganic solutions are often part of the methodology for recovering crystals during biomimetic mineralization experiments performed by various procedures. However, the use of cellulose filter membranes (FM) may cause a problem in in vitro crystallization experiments, because constituents released from the filters into the filtrates can alter the morphology of $\mathrm{CaCO}_{3}$ crystals. Therefore, it is possible to misinterpret data obtained when the effect of specific additives tested in the investigation of biomineralization mechanisms. Herein, we present essential information to avoid such misinterpretations of data obtained from mineralization experiments. $\mathrm{CaCO}_{3}$ was precipitated at room temperature by the gas diffusion method in the presence of FM as support and particularly as filtrates of calcium chloride $\left(\mathrm{CaCl}_{2}\right)$ obtained from various commercial FM. The occurrence or absence of morphological modifications of the calcite and vaterite crystals obtained with different FM correlates well with the different elemental compositions of the solutions where crystals are grown because of the constituents released from the filters into the filtrate. X-ray photoelectron spectroscopy (XPS) data indicate significant differences in the filter elemental composition. We assume that the observed chronological changes in $\mathrm{CaCO}_{3}$ crystal modification could be due to incorporation into the calcite lattice of constituents released from the FM, most likely monomers, oligomers, or short-chain polymers.
\end{abstract}

Keywords: Filter membranes (FM), Gas diffusion, X-ray photoelectron spectroscopy (XPS), calcite.

\section{INTRODUCTION}

The morphological study of crystal growth of $\mathrm{CaCO}_{3}$, which is a typical biomineral observed in seashells, corals and eggshells is important for understanding the essence of structural control in biological functions ${ }^{1-5}$. In non-biological solutions containing synthetic polymers, $\mathrm{CaCO}_{3}$ can grow on various surfaces ${ }^{6,7}$. The results of previous work suggest that the coexistence of specific organic additives, such as L-glutamine and N-acetyl-L-glutamic acid (monomers) and glutathione (tri-peptide), induces characteristic changes in the morphologies of $\mathrm{CaCO}_{3}$ aggregates ${ }^{8}$. It has also been demonstrated that functional groups such as amine, amide, sulfate and carboxylate have significant influence on the process of mineralization ${ }^{9-13}$. A number of approaches have been used to synthesize specific polymorphs of $\mathrm{CaCO}_{3}$ in various forms ${ }^{14}$. These include the use of films, ligand-receptor complexes, block copolymers and synthetic polypeptides ${ }^{15-20}$. It is well known, that the FMs plays a key role in all separation processes, due to its capability to work as physical and selective support for the extraction of chemical species from one phase to the other ${ }^{21,22}$. Filtration of a suspension of $\mathrm{CaCO}_{3}$ particles or other inorganic solutions often are part of the methodology for recovering crystals during biomimetic mineralization experiments performed by various procedures ${ }^{23-25}$. The filters are often membranes composed of mixed esters of cellulose acetate and nitrate. Filtrates of such solutions may cause a problem in in vitro crystallization experiments, because such porous polymer-based filters are not completely stable and constituents released from the filters into the filtrates can alter the morphology of the crystals obtained. Consequently, it is possible to misinterpret data obtained by testing the effect of specific additives on biomimetic mineralization. Here, we present a simple strategy for evaluating the effect of different $\mathrm{FM}$ on $\mathrm{CaCO}_{3}$ crystal morphology. Crystallization experiments were based on the gas diffusion method ${ }^{26}$. The morphology and the size of $\mathrm{CaCO}_{3}$ crystals were analyzed by scanning electron microscopy (SEM), and the elemental composition of FM was determined by X-ray photoelectron spectroscopy (XPS). We show for the first time that, depending on the type of FM used, there is a noticeable effect on $\mathrm{CaCO}_{3}$ crystal morphology. The mechanism of the $\mathrm{CaCO}_{3}$ morphological changes is discussed.

\section{EXPERIMENTAL}

\section{Materials and Methods}

Calcium chloride, ethanol, and tris(hydroxymethyl) aminomethane (TRIS) were obtained from ACS-Merck, and ammonium hydrogen carbonate $\left(\mathrm{NH}_{4} \mathrm{HCO}_{3}\right)$ was from J. T. Baker. All reagents were of the highest available grade. The gas diffusion method was carried out as described elsewhere ${ }^{27}$ -
29. Various FM were accurately weighed and then soaked for $5 \mathrm{~min}, 24 \mathrm{~h}$ or one week in buffered $\mathrm{CaCl}_{2}$ and $\mathrm{CaCl}_{2}$ solutions without TRIS in order to release the constituents from the $\mathrm{FM}$ into the solution. The filtrates of $\mathrm{CaCl}_{2}$ solutions obtained from various FM were used for the in vitro crystallization experiments. For these experiments, $35 \mu 1$ of $200 \mathrm{mM} \mathrm{CaCl}_{2}$ and $3 \mathrm{ml}$ of $25 \mathrm{mM}$ $\mathrm{NH}_{4} \mathrm{HCO}_{3}$ were used. A stock solution of $\mathrm{CaCl}_{2}$ was used for all crystallization experiments, which were carried out at room temperature for $24 \mathrm{~h}$. Four types of commercially available FM were tested: SM-11304 Sartorius Membrane-filter (FM-1), Orange Scientific GyroDisc (FM-2), Gelman Sciences Inc. Sepraphore III (FM-3) and Millipore (FM-4). $\mathrm{CaCO}_{3}$ crystals were rinsed with deionized water and dehydrated in a graded series of $50 \%$ to $100 \%$ ethanol, dried at room temperature, and then coated with gold with an EMS-550 automated sputter coater. Gold-coated crystal samples were loaded into a Tesla BS 343A SEM to observe the microstructure. XPS was used to determine the elemental composition in the FM before and after the crystallization experiment. The spectra were collected on a Physical Electronics 1257 system with an AlKo source $(1486 \mathrm{eV})$ operating at $200 \mathrm{~W}$. Survey scans were used to identify all elements at the FM surface; high resolution scans were used to estimate the elemental composition of carbon $(\mathrm{C})$, oxygen $(\mathrm{O})$ and nitrogen $(\mathrm{N})$.

\section{RESULTS AND DISCUSSION}

The crystallization experiments performed by the gas diffusion method are illustrated in Figure 1.

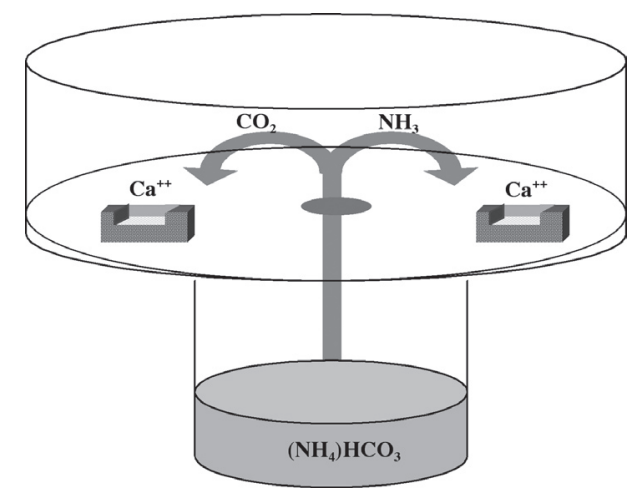

Figure 1. Experimental setup for the gas diffusion method. 
In our preliminary in vitro $\mathrm{CaCO}_{3}$ crystallization experiments using FM as substrates for $24 \mathrm{~h}$ at room temperature we found several time by SEM analysis modified crystals morphology; this surprising and unexpected results occurred with FM-1, FM-2 and FM-4, suggest us that the own FM could have some influence on $\mathrm{CaCO}_{3}$ crystal morphology (Fig. SI-1). This observation was supported by same modified crystals, which also were observed in the bottom of the microbridges far from the FM, indicating that some soluble filter's constituents present in the FM could be released from the cellulose FM into the filtrate. With this in mind and taking into account the difference in the $\mathrm{N}$ elemental composition obtained by XPS analysis in the FM substrates (see Fig.6) we repeat the in vitro $\mathrm{CaCO}_{3}$ crystallization experiments. But we previously put the only ineffective filter (FM-3), which do not contain $\mathrm{N}$ element in the presence either of different concentrations $\mathrm{HNO}_{3}$ solutions (from $1 \mathrm{M}$ to $10^{-8} \mathrm{M}$ ) or vapor at $10 \mathrm{~min}$ (Fig. SI-2). The results of the $\mathrm{CaCO}_{3}$ crystallization using this processed FM-3 support by SEM analysis indicated that experimentally there was possibility to reproduce similar morphological modifications obtained from others FMs. However, in order to complete this investigation and evaluate the effect of some constituents released from FM on $\mathrm{CaCO}_{3}$ crystal morphology we use the present article the filtrate from these FM as a simple strategy during the in vitro $\mathrm{CaCO}_{3}$ crystallization. For that, various solid FM were accurately weighed and then soaked either in buffered $\mathrm{CaCl}_{2}$ or in $\mathrm{CaCl}_{2}$ solutions without TRIS for $24 \mathrm{~h}$ or one week in order to release the constituents of the FM into the solution. The resultant filtrates were used for all crystallization experiments. $\mathrm{CaCO}$ crystals obtained as control experiments grown in the absence of FM filtrate for $24 \mathrm{~h}$ or one week had always a rhombohedral morphology (Fig. SI-3). Although in the present work all the results and discussion are focusing on $24 \mathrm{~h}$ and week. $\mathrm{CaCO}_{3}$ crystallization using filtrates after short filtration process (ca. $5 \mathrm{~min}$ ) of $5 \mathrm{ml}$ buffered $\mathrm{CaCl}_{2}$ and $\mathrm{CaCl}_{2}$ without TRIS solutions were done, as well. (Fig. SI-4). In contrast, different $\mathrm{CaCO}_{3}$ modifications were observed when crystals were grown in the presence of filtrates from various FM (Fig. 2). $\mathrm{CaCO}_{3}$ crystals obtained by using the filtrates from FM-1 resulted in rhombohedral calcite crystals in the size range between 10 to $40 \mu \mathrm{m}$. Crystal edges were partially etched off and were often poorly defined and exhibited several etch pits on their faces (Fig. 2A). When crystallization experiments were carried out with the filtrate from FM-2, some corners of the crystals were rounded, but the crystals faces were smooth and exhibited no etch pits (Fig. 2B). The size of these crystals were from 10 to $30 \mu \mathrm{m}$. Crystals grown in the filtrate from FM-3 resulted in a mixture of single spheres, spherical aggregates made of plates, and solid rhombohedra (Fig. 2C). The spherical crystals are uniform in size at about $20 \mu \mathrm{m}$. Rhombohedral crystals showed smooth surfaces, while the surfaces of the spherical crystals are composed of several tiny uniform particles (Fig. 2C insert). Stacked rhombohedral crystal aggregates were formed in the presence of filtrate from FM-4 (Fig. 2D). These stacked crystals are 10 and $50 \mu \mathrm{m}$ in size. Like crystals grown in the presence of filtrate from FM-2 (Fig. 2b), these crystals had smooth surfaces with no etch pits (Fig. 2D).
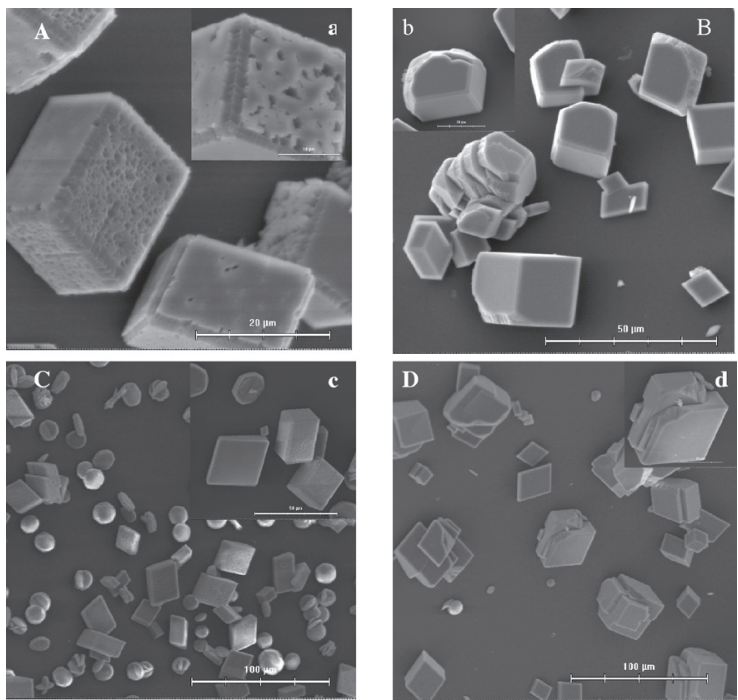

Figure 2. SEM of $\mathrm{CaCO}_{3}$ crystals obtained in the presence of filtrate from FM-1 (A), FM-2 (B), FM-3 (C) or FM-4 (D). The filtrates for this experiment were prepared by soaking the filters in buffered $\mathrm{CaCl}_{2}$ solution for $24 \mathrm{~h}$.
With filtrates of $\mathrm{CaCl}_{2}$ solutions lacking TRIS under the same reaction conditions, similar crystal modifications were found (Fig. 3). The use of filtrate from FM-1 resulted in rhombohedral calcite crystals exhibiting occasional etch pits on the surface. In this case, calcite crystals are 10 to $40 \mu \mathrm{m}$ in size and their edges are well defined with smooth surfaces (Fig. 3A). Like the crystals grown in the presence of filtrate prepared from FM-2 with buffered $\mathrm{CaCl}_{2}$, crystals with rounded end faces were obtained in the presence of filtrate prepared from FM-2 with $\mathrm{CaCl}_{2}$ lacking TRIS. $\mathrm{CaCO}_{3}$ precipitation in TRIS-free filtrate from FM-3 resulted in rhombohedral calcite crystals, which exhibited etch pits on the surface (Fig. 3C). Similar to crystals formed in buffered FM-4 filtrate, aggregated $\mathrm{CaCO}_{3}$ crystals were formed in the presence of TRIS-free FM-4 filtrate, but these crystals are elongated in the c-direction.
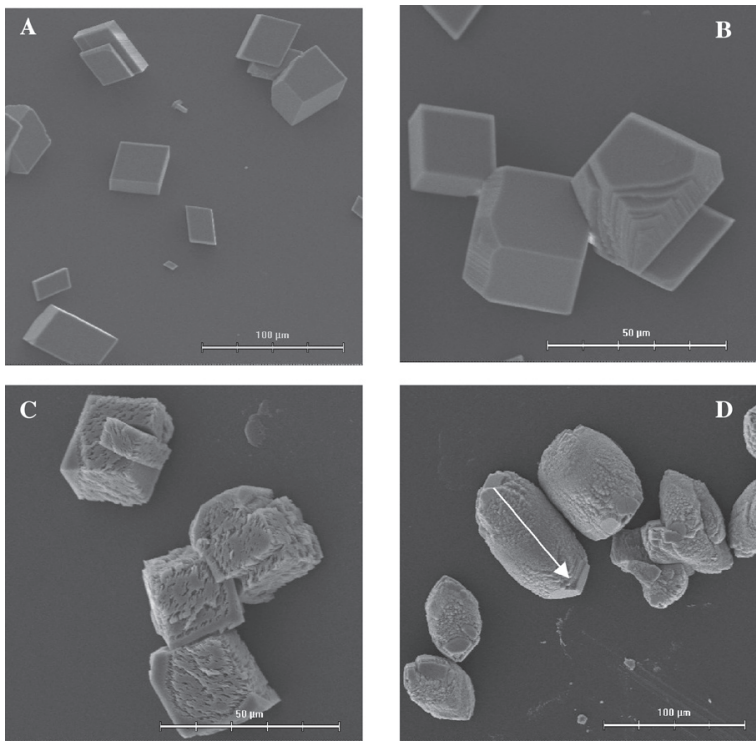

Figure 3. SEM of $\mathrm{CaCO}_{3}$ crystals obtained in the presence of filtrate prepared from FM-1 (A), FM-2 (B), FM-3 (C), and FM-4 (D). The filtrates for this experiment were prepared by soaking the filters in aqueous (i.e., TRISfree) $\mathrm{CaCl}_{2}$ solution for $24 \mathrm{~h}$.

Another set of crystallization experiments were performed with filtrates prepared by soaking FM-1, FM-2, FM-3, and FM-4 in either buffered $\mathrm{CaCl}_{2}$ or $\mathrm{CaCl}_{2}$ solutions without TRIS for a longer period of time, one week rather than $24 \mathrm{~h}$. When the resultant filtrates were used to repeat the $\mathrm{CaCO}$, crystallization experiments under the same reaction conditions, the results were more striking. Using the filtrates from FM-1 resulted in rhombohedral calcite with the end faces of the crystals and the surfaces almost etched off and the well defined rhombohedral shape virtually lost (Fig. 4A). These $\mathrm{CaCO}_{3}$ crystals are in the size range of 10 to $50 \mu \mathrm{m}$. Rounded and aggregates calcite crystals similar to those in Fig. 2B and D were formed by using the one-week filtrate from FM-2 and FM-4, respectively (Fig. 4C and D). Closer examination of these crystal surfaces reveals that the faces contain terraces (Fig. $4 \mathrm{~B}$ and D). However, in the case of one-week filtrate from FM-3, the tendency to form aggregates of spherical crystal plates was more pronounced (Fig. 4C) compared to 24-h FM-3 filtrate (Fig. 2C). The crystals sizes were similar for crystals grown in the presence of either 24-h or one-week buffered $\mathrm{CaCl}_{2}$ filtrate. This filtrate exerted a strong inhibitory effect on growing rhombohedral calcite crystals, and only a very few rhombohedral calcite crystals were observed (Fig. 4C). A higher magnification image shows that these spherical surfaces are smooth and composed of several plates (Fig. $4 \mathrm{c}$ inset). 

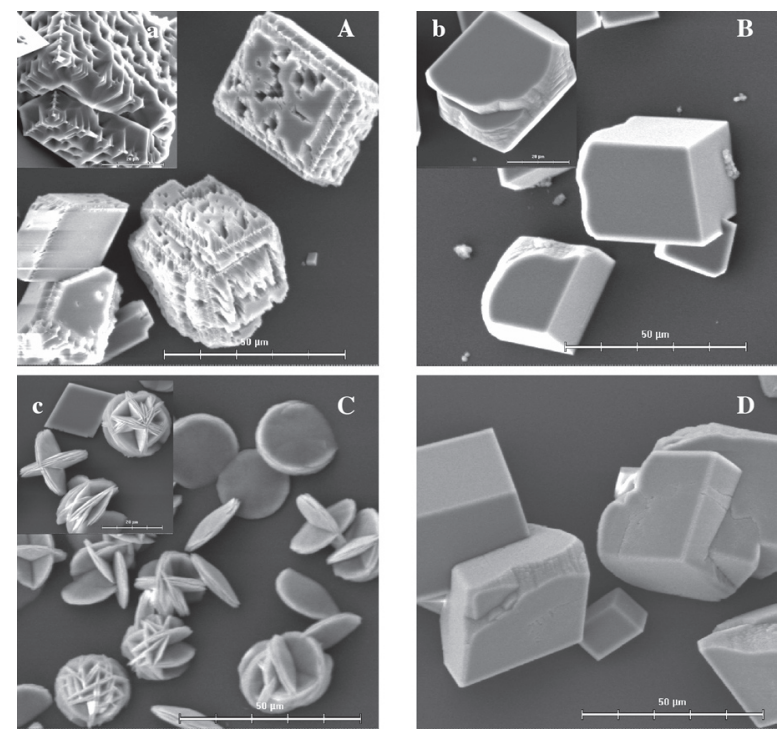

Figure 4. $\mathrm{SEM}$ of $\mathrm{CaCO}_{3}$ crystals obtained in the presence of filtrate from FM-1 (A), FM-2 (B), FM-3 (C), or FM-4 (D). The filtrates for this experiment were prepared by soaking the filters in buffered $\mathrm{CaCl}_{2}$ solution for one week.

In the presence of one-week filtrates of $\mathrm{FM}-1$ prepared with $\mathrm{CaCl}_{2}$ lacking TRIS, rhombohedral calcite crystals were obtained (Fig. 5A). These crystals were rather uniform in shape compared to those in Fig. 4A. Calcite crystals and aggregates with rounded edges similar to those in Fig. 2B and 3B were formed in the presence of the one-week, TRIS-free filtrate of FM-2 (Fig. 5B). As with the other FM-3 filtrates, using the one-week, TRIS-free filtrate from FM-3 resulted in rhombohedral calcite with several etch pits on the surface (Fig. 5C). With the one-week, TRIS-free FM-4 filtrate, only aggregated and truncated $\mathrm{CaCO}_{3}$ crystals were formed (Fig. 5D). With filtrates from FM-4, etch pits were never observed, and only smooth surfaces were found.
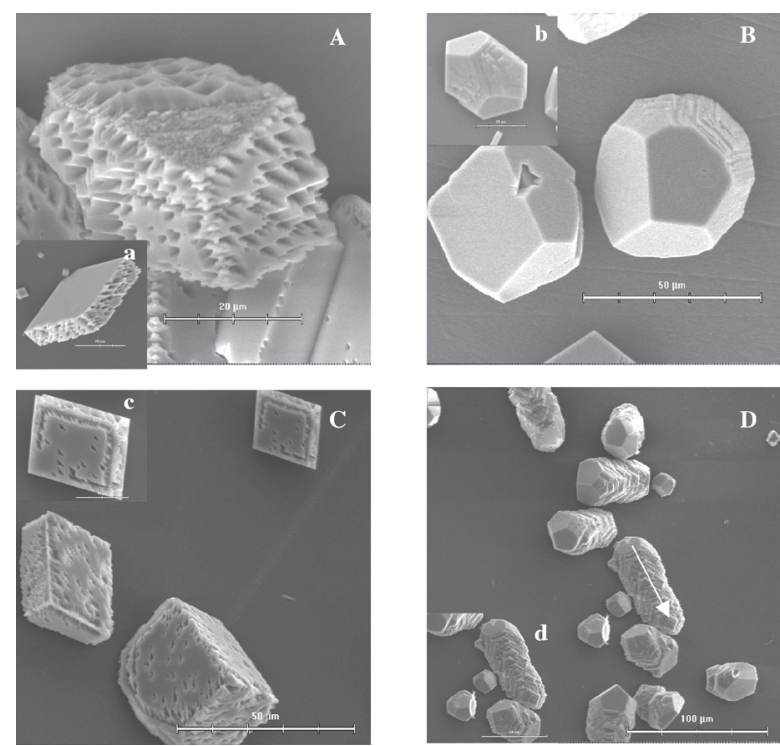

Figure 5. SEM of $\mathrm{CaCO}_{3}$ crystals obtained in the presence of filtrate prepared from FM-1 (A), FM-2 (B), FM-3 (C), and FM-4 (D). The filtrates for this experiment were prepared by soaking the filters in aqueous (i.e., TRISfree) $\mathrm{CaCl}_{2}$ solution for one week.
The XPS was used as a direct probe of surface elemental composition and provides chemical shift information of the starting FM. XPS data were recorded before (Fig. 6) and after soaking the filter in $\mathrm{CaCl}_{2}$ solution without TRIS for 24 h (Fig. 7) as follows: 1) broad scans (1-eV step) from 1100 to $0 \mathrm{eV}$ to identify the elements at the surface, which allows detection of $\mathrm{C}, \mathrm{O}$, and $\mathrm{N}$, but not other elements; 2) high resolution scans of the $\mathrm{O} 1 \mathrm{~s}, \mathrm{~N} 1 \mathrm{~s}$, and $\mathrm{C} 1 \mathrm{~s}$ photoemissions. The XPS survey scan spectra of starting FM are shown in Fig. 6. The only FM exhibiting no N is FM-3 (Fig. 6A). The spectra of the other FM are similar, and all exhibit a signal for $\mathrm{N}$ as is shown only for FM-2 (Fig. 6B). The insets (Fig. $6 \mathrm{c}$ and d) are high resolution spectra of the C1s and N1s photoemissions from both FM, where the lower tracing corresponds to the N-free filter (Fig. 6A). The estimated initial elemental composition of the $\mathrm{O} 1 \mathrm{~s}, \mathrm{C} 1 \mathrm{~s}$, and N1s from the starting FM is summarized in Table 1. The high resolution measurement confirms that FM-3 contains no detectable N, because the N1s signal is at the noise level with a detection limit estimated to be below 1/1000 (Fig. 6d2). The N1s peak from the FM-2 sample is clear and is positioned around $405 \mathrm{eV}$ with a FWHM of $1.89 \mathrm{eV}$ (Fig. 6d1). Different FM show qualitative differences in the $\mathrm{C} 1 \mathrm{~s}$ signal (Fig. 6c, inset).

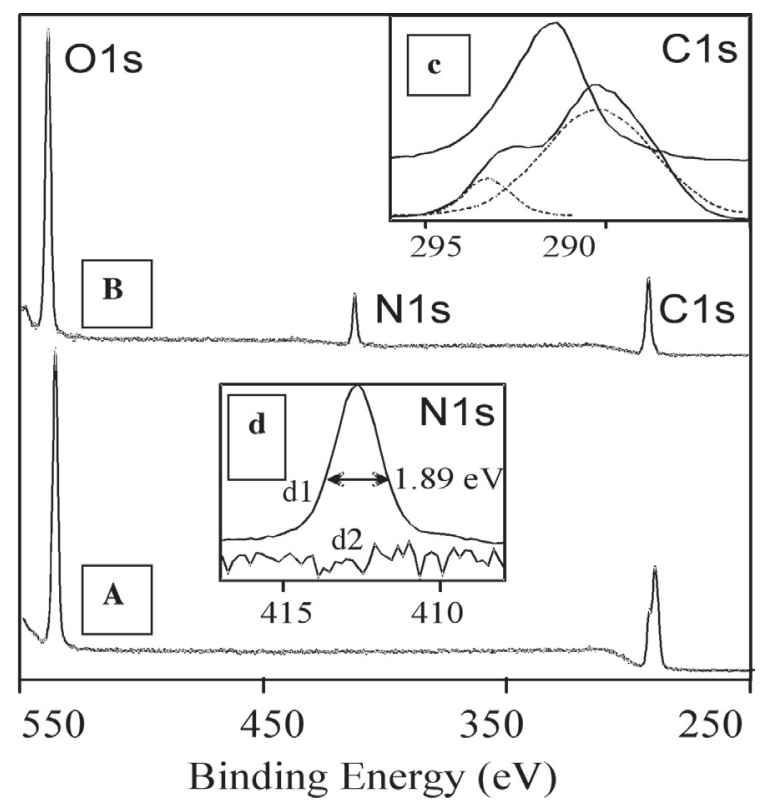

Figure 6. XPS survey scan spectra of FM papers FM-3 (A) and FM-2 (B). The inset (c) represents C1s of all FM filters and (d) N1s of FM-2 (d1) and FM-3 (d2), respectively.

Table 1. Summary of the description for all FM.

\begin{tabular}{|c|c|c|c|c|}
\hline FM & & & & \\
\hline Name / type & $\begin{array}{c}\text { Sartorius- } \\
\text { Membranfilter }\end{array}$ & $\begin{array}{c}\text { Orange } \\
\text { Scientific } \\
\text { GyroDisc }\end{array}$ & $\begin{array}{c}\text { Sepraphore } \\
\text { III }\end{array}$ & Millipore /HA \\
\hline Abbreviation & FM-1 & FM-2 & FM-3 & FM-4 \\
\hline $\begin{array}{l}\text { Filter material } \\
\text { (composition) }\end{array}$ & $\begin{array}{l}\text { Cellulose } \\
\text { nitrate }\end{array}$ & $\begin{array}{c}\text { Mixed } \\
\text { cellulose } \\
\text { esters }\end{array}$ & $\begin{array}{c}\text { Cellulose } \\
\text { Polyacetate }\end{array}$ & $\begin{array}{c}\text { Mixed cellulose } \\
\text { esters }\end{array}$ \\
\hline $\begin{array}{c}\text { XPS } \\
\text { (before } \\
\text { soaking) }\end{array}$ & $\begin{array}{c}\mathrm{O}: \mathrm{C}: \mathrm{N}= \\
52: 42: 6\end{array}$ & $\begin{array}{l}\mathrm{O}: \mathrm{C}: \mathrm{N}= \\
55: 35: 10\end{array}$ & $\begin{array}{l}\mathrm{O}: \mathrm{C}: \mathrm{N}= \\
44: 56: 0\end{array}$ & $\begin{array}{c}\mathrm{O}: \mathrm{C}: \mathrm{N}= \\
50: 43: 7\end{array}$ \\
\hline $\begin{array}{c}\text { XPS } \\
\text { (after } \\
\text { soaking) }\end{array}$ & $\begin{array}{c}\mathrm{O}: \mathrm{C}: \mathrm{N}= \\
52: 42: 6\end{array}$ & $\begin{array}{c}\mathrm{O}: \mathrm{C}: \mathrm{N}= \\
50: 50: 0\end{array}$ & $\begin{array}{c}\mathrm{O}: \mathrm{C}: \mathrm{N}= \\
53: 47: 0\end{array}$ & $\mathrm{O}: \mathrm{C}: \mathrm{N}=52: 44: 4$ \\
\hline
\end{tabular}

Moreover, XPS analysis was carried out on the FM after soaking in $\mathrm{CaCl}_{2}$ solutions without TRIS for 24h (Fig. 7). The XPS spectra of FM-1, FM3 , and FM-4 are similar to the spectra obtained before soaking. That is, the spectra of FM-1 and FM-4 exhibit a signal for N (Fig. 7A and D), and the XPS spectrum of FM-3 confirmed the absence of N, as is the case for FM-3 before soaking (Fig. 7C). However, the XPS spectrum of FM-2 (Fig. 7B) shows no detectable $\mathrm{N}$, which indicates the total transfer of $\mathrm{N}$ from the FM-2 paper to the 
filtrate. The elemental compositions of the FM and FM after soaking are shown in Table 1. Fig. 7E shows the N1s photoemissions from all FM.

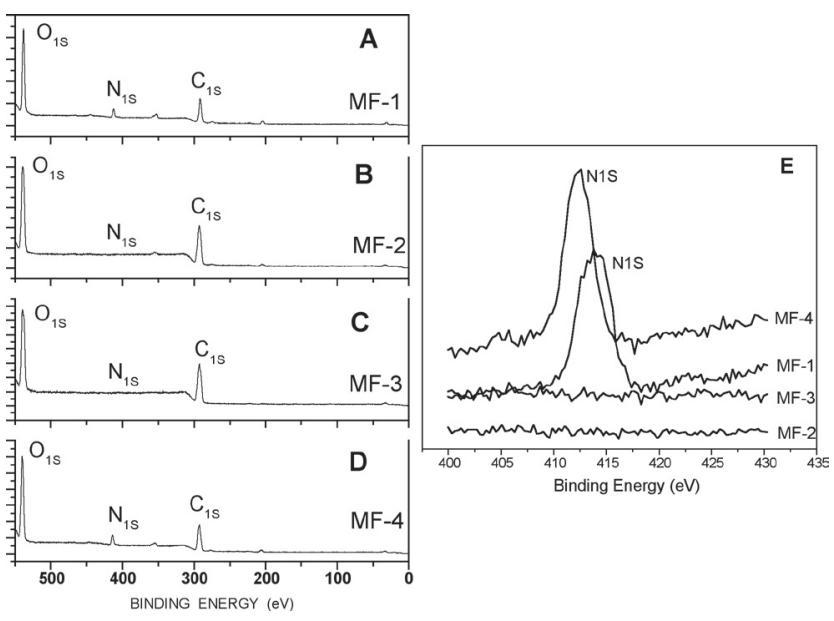

Figure 7. XPS survey scan spectra of $\mathrm{FM}$ after soaking in $\mathrm{CaCl}_{2}$ solution without TRIS for 24 h. A) FM-1, B) FM-2, C) FM-3, D) FM-4, E) photoemission of N1s of all FM.

In order to determine the elemental compositions on the surface of $\mathrm{CaCO}_{3}$ crystals, we utilized the EDS technique. For this analysis, we used two different types of FM, FM-1 and FM-3, which contain N and no N, respectively. Figure 8 shows the SEM-EDS spectra of $\mathrm{CaCO}_{3}$ crystals obtained in the presence of filtrates of FM-1 and FM-3 after soaking in $\mathrm{CaCl}_{2}$ solutions without TRIS for one week.
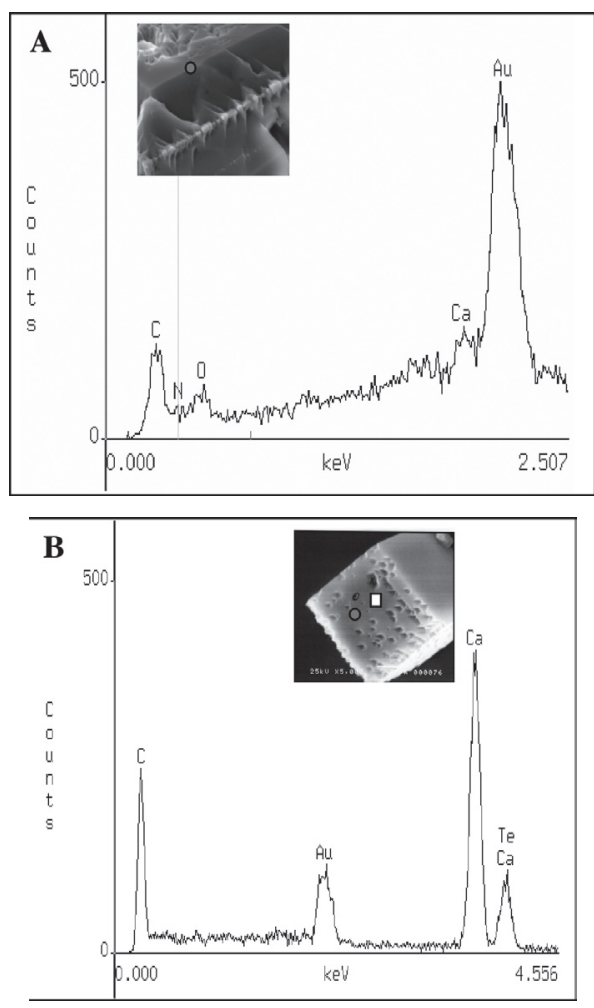

Figure 8. SEM-EDS spectra of $\mathrm{CaCO}_{3}$ crystals grown in the presence of filtrates prepared by soaking the filters in $\mathrm{CaCl}_{2}$ without TRIS like: FM-1 after one week (A) and FM-3 after one week (B). The circle (o) and square () symbols in the micrographs indicate smooth and rough or holes parts.
A set of crystallization experiments were carried out with buffered or unbuffered $\mathrm{CaCl}_{2}$ solutions. Though TRIS contains the $\mathrm{N}$ atom, to verify that $\mathrm{N}$ from the $\mathrm{FM}$ has some influence on $\mathrm{CaCO}_{3}$ modification, $\mathrm{CaCO}_{3}$ crystals were grown in media consisting of filtrates of FM prepared with either TRISbuffered $\mathrm{CaCl}_{2}$ or $\mathrm{CaCl}_{2}$ without TRIS. We determined that the filtrates prepared with unbuffered $\mathrm{CaCl}_{2}$ are consistently lower in $\mathrm{pH}$ than the filtrates prepared with buffered $\mathrm{CaCl}_{2}$, but we believe that this difference in $\mathrm{pH}$ did not act as a modifier of the $\mathrm{CaCO}_{3}$ behavior (see Table 2). Rather, the N-containing constituents released from the filter act to modify the nucleated calcite crystals. Figures 2-5 show SEM images that summarize the morphology of the nucleated $\mathrm{CaCO}_{3}$ crystals. In general, the morphological behavior of the TRISbuffered system more strongly resembles that of unbuffered $\mathrm{CaCl}_{2}$ solutions. The control experiment leads to crystals of rhombohedra with mostly flat and smooth (104) main surfaces (Fig. SI-1) without etch pits. Calcite was the major polymorph nucleated in the presence of filtrates prepared from FM-1, 2, and 4 with either TRIS-buffered or unbuffered $\mathrm{CaCl}_{2}$ solutions for $24 \mathrm{~h}$ or one week. In these situations, calcite nucleation is broadly stabilized. The appearance of the thermodynamically most stable phase of $\mathrm{CaCO}_{3}$ could be due to a number of factors. In the control system, the energy barrier to nucleation for calcite is higher than the barrier for vaterite. This is probably an expression of Ostwals's step rule (that is, a metastable phase's nucleation rate can be higher than those of the stable phase $)^{30}$. An attempt with a filtrate from FM-3 prepared with buffered $\mathrm{CaCl}_{2}$ for $24 \mathrm{~h}$ and one week was dominated by the vaterite polymorph (Fig. $2 \mathrm{C}$ and $4 \mathrm{C}$ ). In this case, the reverse trend implies that the carboxylates from the FM-3 paper are either reducing the barrier to calcite nucleation or increasing the barrier to vaterite nucleation (e.g., a lowering of the local supersaturation). By increasing the soaking time in case of FM-3, the tendency to form aggregates of spherical crystal plates is more evident. However, $\mathrm{CaCl}_{2}$ solutions without TRIS show a tendency to form rhombohedral calcite crystals as occurred in the case of FM-1. The $\mathrm{CaCO}_{3}$ morphogenesis obtained with the filtrates of FM-1 and FM-2 in both buffered and unbuffered $\mathrm{CaCl}_{2}$ solutions show similar behavior. Crystals obtained with the filtrate of FM-1 after $24 \mathrm{~h}$ of soaking for both reaction media show prominent etch pits. Control calcite crystals exposed to similar conditions show no etch pits. The appearance of the crystals was found to change for the one week soaking times for both reaction media. Crystals obtained with the filtrate of FM-1 for both media at one week soaking times showed severely affected surfaces resulting from dissolution. The etch pits observed in Fig. 4a and 5a for one week filtrates do not have crystallographic symmetry and penetrate deep into the crystals. The original rhombohedra completely lose their shape. The reason for these etch pits is that the nitrate of the cellulose nitrate released from FM became the etching agent as time progressed. It is possible that as the $\mathrm{Ca}^{2+}$ supply was depleted (due to crystal growth), the negative group of the nitrate from the FM, which is known to bind $\mathrm{Ca}^{2+}$, became "Ca-starved" and began dissolving the crystals to reclaim the $\mathrm{Ca}^{2+}$. To test this, the same crystallization experiment with FM-3 without soaking was repeated and resulted in crystals with a smooth surface having no etch pits, similar in morphology to that of control calcite crystals (Fig. SI-1). This suggests that the acid group from cellulose nitrate is causing the formation of the etch pits by acting in solution on the formed crystals. Both the unique surface features that develop with time and the etch pit behavior of the $\mathrm{CaCO}_{3}$ crystals indicate that the functionalities of cellulose nitrate alter the growth and physical characteristics of these calcite crystals compared to those of control calcite crystals. A probable cause of these observations is the occlusion of nitrate groups released inside the growing crystal lattice. The nitrate groups which are present on the surface can hinder dissolution, while nitrate groups inside the crystalline lattice may enhance dissolution. This may be the reason why the crystals develop deep etch pits when they are grown in one-week filtrates. In the case of filtrates from FM-2 for both reaction media (Fig. 2b, 3b, 4b, and 5b), rhombohedral calcite crystals are formed. The crystals are rounded with terraces containing faces. In both media after soaking for $24 \mathrm{~h}$ and one week, there is no difference in $\mathrm{CaCO}_{3}$ morphological behavior, which indicates that there is no effect of increasing the soaking time. XPS analysis before and after soaking FM shows that at $24 \mathrm{~h}$ of soaking, all the $\mathrm{N}$ content is completely transferred to the filtrate $\mathrm{CaCl}_{2}$ solution (Table 1). This is why one week of soaking does not produce any additional effect on morphological behavior for both media, because there is no more N present in the FM-2 after soaking for $24 \mathrm{~h}$

Crystal growth in the presence of filtrate from FM-4 after soaking for $24 \mathrm{~h}$ and one week in $\mathrm{CaCl}_{2}$ solution without TRIS leads to the formation of calcite crystals elongated in the (110) face. Similar behavior was also observed by Mann et al. with $\alpha, \omega$-dicarboxylates as an additive ${ }^{31}$. Calcite crystal faces parallel to the $c$-axis may have the carbonate group oriented perpendicular to the face. These faces may be stabilized via stereoselective adsorption of the 
acids via bidentate binding ${ }^{31}$ of the carboxylate groups coming from the FM-4. The N-containing constituents released from FM-4 can block the specific face of calcite, which leads to an elongation process. A similar blocking process by ammonia on one negative (001) face has been described by Dupont $e t$ al. and by Sedlak et al. ${ }^{32,33}$. In the case of filtrates prepared with buffered $\mathrm{CaCl}_{2}$ for $24 \mathrm{~h}$ and one week, we did not observe this trend probably because the composition of the $\mathrm{N}$ remains constant due to buffering of the system. The observed flat surface of the growth edge of calcite crystals grown in the presence of filtrates from FM-2 and 4 (Fig. 2 to $5 \mathrm{~B}$ and D) are due to surface minimization energy produced by the N-containing constituents released from FM-2 and 4. To confirm the results which show that the constituents released from the filters to the filtrates can alter the nucleation of $\mathrm{CaCO}_{3}$, the crystallization experiments were repeated three times. In each experiment, similar results were obtained, in that the constituents released from the filters act to modify $\mathrm{CaCO}_{3}$ crystal morphology in both reaction media.

Table 2. $\mathrm{pH}$ of the filtrates from TRIS-buffered and unbuffered $\mathrm{CaCl}_{2}$ solutions prepared by soaking FM for $24 \mathrm{~h}$ or one week.

\begin{tabular}{|c|c|c|c|c|c|c|}
\hline \multirow{2}{*}{$\begin{array}{c}\text { time of } \\
\text { soaking }\end{array}$} & \multirow{2}{*}{$\begin{array}{c}\text { filtrate } \\
\text { solutions }\end{array}$} & $\begin{array}{c}\text { filter/ } \\
\mathrm{pH}\end{array}$ & $\begin{array}{c}\text { filter/ } \\
\mathrm{pH}\end{array}$ & $\begin{array}{c}\text { filter/ } \\
\mathrm{pH}\end{array}$ & $\begin{array}{c}\text { filter/ } \\
\mathrm{pH}\end{array}$ & $\begin{array}{c}\text { control/ } \\
\mathrm{pH}\end{array}$ \\
\cline { 3 - 7 } & $\mathrm{FM}-1$ & $\mathrm{FM}-2$ & $\mathrm{FM}-3$ & FM-4 & control \\
\hline \multirow{2}{*}{$24 \mathrm{~h}$} & $\left(\mathrm{CaCl}_{2} / \mathrm{TRIS}\right)$ & 8.88 & 8.90 & 8.87 & 8.89 & 8.84 \\
\cline { 2 - 7 } & $\left(\mathrm{CaCl}_{2} / \mathrm{H}_{2} \mathrm{O}\right)$ & 7.10 & 7.15 & 7.11 & 6.50 & 7.55 \\
\hline \multirow{2}{*}{ 1 week } & $\left(\mathrm{CaCl}_{2} / \mathrm{TRIS}\right)$ & 8.74 & 8.65 & 8.64 & 8.72 & 8.80 \\
\cline { 2 - 7 } & $\left(\mathrm{CaCl}_{2} / \mathrm{H}_{2} \mathrm{O}\right)$ & 6.98 & 6.93 & 6.96 & 6.21 & 7.37 \\
\hline
\end{tabular}

The XPS analysis demonstrated that the $\mathrm{N}$ content changes after soaking. Moreover, we found that the photoemission signal from the N-free filter (Fig. 6, FM-3; bottom) exhibits a shoulder and can be decomposed into two peaks at $284.5 \mathrm{eV}$ (main) and 287.3 (secondary). This indicates that $\mathrm{C}$ is present in at least two different chemical states. The N-containing filter (Fig. 6, FM-2) exhibits only a single peak, which suggests that the process by which $\mathrm{N}$ is incorporated into the filter eliminates one of these chemical states. The XPS analysis of all FM after being soaked in $\mathrm{CaCl}_{2}$ solution for 24h (Fig. 7) indicates that the photoemission of the N1s is lower, which suggests that the release of the Ncontaining constituents always occurred. But in the case of FM-2, the complete disappearance of the photoemission of the $\mathrm{N} 1$ indicates the total release of $\mathrm{N}$ containing constituents. This observation suggests that the presence of different $\mathrm{N}$ of FM is crucial and could be involved during the nucleation of the $\mathrm{CaCO}_{3}$ crystallization. An electrostatic interaction of the $\mathrm{N}$ with some specific faces of $\mathrm{CaCO}_{3}$ crystals has been demonstrated previously ${ }^{34,35}$.

\section{CONCLUSIONS}

The experimental results obtained in this investigation provide important information regarding in vitro $\mathrm{CaCO}_{3}$ crystallization in the presence of $\mathrm{FM}$ and particularly of the filtrates from different FM. Our results suggest that the modifications of the $\mathrm{CaCO}_{3}$ crystals are basically due to of the differences in the chemical nature of the FM, but also depend of the filtration time and experimental $\mathrm{pH}$ condition. Thus, when the in vitro crystallization experiments were carried out on the FM surfaces we found only the FM-3 as an inert filter until $24 \mathrm{~h}$. Moreover, if we use the filtrate from FM-3 as additive no modified crystals were found but only for short filtration period (SI-Fig.4). For long filtration period all filtrates from these FM altered the final crystals morphology. Therefore, we believe that these undesired additional effects could lead to misinterpretation of the real effect of selected additives during in vitro crystallization experiments.

\section{ACKNOWELEDGEMENTS}

This research was supported by FONDAP 11980002 granted by the Chilean Council for Science and Technology (CONICYT) and Fundación Andes C-14060/31. Fundación Andes provided the surface analysis facilities under grant C10810-2. The authors are grateful to Dr. David Carrino for a critical review of the manuscript.

\section{REFERENCES}

1. H. A. Lowenstam, S. Weiner, On Biomineralization, Oxford, UK: Oxford University Press; 1989.

2. S. Mann, Biomineralization, Oxford, UK: Oxford University Press; 2001.

3. P. M. Dove, J. J. De Yoreo, S. Weiner, Rev. in Mineralogy and Geochemistry. Biomineralization, 54, 151 (2003).

4. J. L. Arias, M. S. Fernandez, Mater. Charact. 50, 189, (2003).

5. J. L. Arias, D. Fink, S-Q. Xiao, A. H. Heuer, A. I. Caplan, Intern. Rev. Cytol., 145, 217, (1993).

6. S. Mann, G.A. Ozin, Nature, 382, 313, (1996).

7. F. C. Meldrum, Intern. Mat. Rev., 48, 187, (2003).

8. R. K. Pai, Ph.D. Dissertation, University of Ulm, Germany. 2005, p. 53.

9. J. Aizenberg, A. J. Black, G. M. Whitesides, Nature, 398, 495, (1999).

10. J. J. Aizenberg, J. Cryst. Growth, 211, 143, (2000).

11. E. Dalas, P. Klepetsanis, P.G. Koutsoukos, Langmuir 15, 8322, (1999).

12. R. K. Pai, S. Hild, A. Ziegler, O. Marti, Langmuir 20, 3123, (2004).

13. L. Addadi, J. Moradian, E. Shay, N.G. Maroudas, S. Weiner, Biophys. 84, 2732, (1987).

14. R.K. Pai, S. Pillai, Cryst. Growth Des. 7, 215, (2007).

15. G. Falini, S. Femani, M. Gazzano, A. Ripamonti, Chem. Eur. J. 3, 1807, (1997).

16. N. Blagden, B.R. Heywood, Cryst. Growth Des. 3, 167, (2003).

17. H. Cölfen, L.M. Qi, Chem. Eur. J. 7, 106, (2001).

18. A. Neira-Carrillo, M. Yazdani-Pedram, J. Retuert, M. Diaz-Dosque, S. Gallois, J. L. Arias, J. Colloid Interface Sci., 286, 134, (2005).

19. H. Cölfen, S. Mann, J. Mater. Chem. 14, 2269, (2004).

20. D. B. DeOliveira, R. A. Laureen, J. Am. Chem. Soc. 119, 10627, (1997).

21. T. Franken. Membr. Technol. 97, 7, (1998).

22. A. Gugliuzza, E. Drioli. J. Membr. Sci. 300, 51, (2007).

23. R. Lakshminarayanan, S. Valiyaveettil, Cryst. Growth Des. 3, 611, (2003).

24. T. Jung, W-S. Kim, C.K. Choi, Mater. Sci. \& Engin. C24, 31, (2004).

25. Y. Kitano, K. Park, D.W. Hood, J. Geophys. Res. 67, 4873, (1962).

26. J. M. Domínguez-Vera, J. Gautron, J. M. García-Ruiz, Y. Nys, Poultry Sci. 79, 901, (2000).

27. J. I. Arias, C. Jure, J. P. Wiff, M.S. Fernández, V. Fuenzalida, J. L. Arias, Mat. Res. Soc. Proc. 711 , 243, (2002).

28. A. Neira-Carrillo, M. S. Fernández, J. Retuert, J. L. Arias, Mat. Res. Soc. Proc. EXS-1, 321, (2003).

29. M. S. Fernández, K. Passalacqua, J. I. Arias, J. L. Arias, J. Struct. Biol. 148, 1, (2004)

30. I. V. Markov, Crystal Growth and Epitaxy; World Scientific: Singapore, 1995.

31. S. Mann, M. Didymus, N.P. Sanderson, R.H. Brigid, E.J. Aso-Samper, J. Chem. Soc. Faraday Trans., 86, 1873, (1990).

32. L. Dupont, F. Portemer, M. Figlarz, J. Mater. Chem. 7, 797, (1997).

33. M. Sedlak, H. Cölfen, Macromol. Chem. Phys. 2002, 587, (2001).

34. C. A. Orme, A. Noy, A. Wierzbicki, M.T. McBride, M. Grantham, H. H. Teng, P.M. Dove, J.J. De Yoreo, Nature, 411, 775, (2001).

35. D. Volkmer, M. Fricke, C. Agena, J. Mattay, J. Mater. Chem, 14, 2249, (2004). 